\title{
Survival Following Stereotactic Radiotherapy for Recurrent High Grade Gliomas
}

\author{
Gulcin ERTAS, Ali R. UCER, Yıldız Y. GUNEY, Gulhan G. AVCI, M. Bedri ALTUNDAG, \\ Hayati ABANUZ, Atilla DEMIRKASIMOGLU, Tamer CALIKOGLU \\ Ankara Oncology Training and Research Hospital, Department of Radiation Oncology, Ankara, TURKEY
}

\begin{abstract}
We aimed to report our stereotactic radiotherapy experience with Cyberknife (Accuray, Inc., Sunnyvale, CA, USA) for patients with recurrent high grade glial tumor. Forty-two patients with histologically proven malign glioma (30 glioblastoma, 12 anaplastic astrocytoma) and also treated with previous conventional fractioned radiotherapy underwent stereotactic radiotherapy via Cyberknife for their recurrent tumor in Ankara Oncology Hospital between July 2009-and September 2012. The median follow up time was 30 months (range, 8-144 months) after diagnosis and 10 months (range, 1-38 months) from stereotactic radiotherapy (SRT). The median survival from SRT are 8 months for glioblastoma patients and 11 months for grade 3 malign glioma patients $(p=0.157)$. The median survival from SRT are 9 months and 11 months in patients given chemotherapy and not given, respectively $(p=0.436)$. The median survival from SRT are 10 months in patients reoperated and 9 months not reoperated ( $p=0.827$ ). Stereotactic radiotherapy is an effective treatment modality in patients with recurrent glial tumor.
\end{abstract}

Keywords: Cyberknife, Glioma, Stereotactic radiotherapy

\section{ÖZET}

\section{Yinelemiş Yüksek Grade Gliomlarda Stereotaktik Radyoterapi Sonrası Sağkalım}

Yinelemiş yüksek gradlı glial tümörlü 42 hastada cyberknife deneyimimizi sunmaktayız. Ankara Onkoloji Hastanesinde, Temmuz 2009 ile Eylül 2012 tarihleri arasında yinelemiş 42 malign gliomlu (30 glioblastom, 12 anaplastik astrositom) hastaya Cyberknife (Accuray, Inc., Sunnyvale, CA, USA) ile stereotaktik radyoterapi uygulandı. Teşhisden sonraki ortanca takip zamanı 30 ay (aralık 8-144 ay), stereotaktik radyoterapi (SRT) sonrası ortanca takip zamanı 10 ay (aralık, 1-38 ay). Ortanca sağkalım, SRT sonrası glioblastom hastaları için 8 ay iken grade 3 gliomlu hastalar için 11 ay idi $(p=0.157)$. Stereotaktik radyoterapi sonrası ortanca sağkalım, kemoterapi alan hastalarda 9 ay iken almayanlarda 11 ay idi ( $p=0.436)$. Nüks sonrası tekrar opere edilebilen hastalarda SRT sonrası ortanca sağkalım 10 ay iken opere edilemeyenlerde 9 ay bulundu( $p=0.827)$. Yinelemiş glial tümürlü hastaların tedavisinde stereotaktik radyoterapi etkin bir seçenektir.

Anahtar Kelimeler: Cyberknife, Glial tümör, Stereotaktik radyoterapi 


\section{INTRODUCTION}

High grade gliomas account for approximately half of all primary brain tumors in adults. Glioblastoma multiforme (GBM) accounts for approximately $75 \%$ of all high grade gliomas. Standart treatment of patients with GBM is surgical resection followed by adjuvant radiotherapy. Maximal surgical resection followed by radiotherapy with concomitant and adjuvant temozolomide improved survival. ${ }^{1,2,3,4} \mathrm{But}$ the prognosis for patient with GBM generally is poor and median survival time approximately one year.

Anaplastic gliomas constitute approximately 25\% of high grade gliomas in adults. Anaplastic gliomas, comprising anaplastic astrocytomas, anaplastic oligodendrogliomas, and anaplastic mixed oligoastrocytomas, correspond to WHO (World Health Organization) grade 3 . The patients with anaplastic astrocytoma have a median survival of approximately three years following diagnosis.

Several therapeutic options which consists of chemotherapy, palliative debulking surgery and repeated radiotherapy with stereotactic radiosurgery or stereotactic radiotherapy ( SRT) has been considered for patients with recurrent GBM. ${ }^{5-12}$

Stereotactic radiosurgery or SRT methods has been explored for treating recurrent glioma., ${ }^{5,8,13,14,15}$ Robotically guided radiosurgery system (Cyberknife, Accuray Inc,Sunnyvale, CA,USA) consists of 6 MV linear accelerator mounted on robot arm. ${ }^{16}$ This system uses image guidance system and computer controlled robot to correct patient movement during treatment.The position of the robot is updated with real time radiographs taken during treatment. It use large number of beams (100-150 for cranial tumors) and provides local dose escalation on the targeted area without damaging surrounding normal tissue. Because of this advantages, it can be useful option for treatment of recurrent glial tumors.Therefore, we considered to review the effectiveness of stereotactic radiotherapy in the treatment of recurrent high grade glial tumor.

\section{PATIENTS AND METHODS}

\section{Patients}

We examined survival rates of 42 patients with high grade glial tumor who treated with CyberKnife stereotactic radiotherapy at the time of tumor recur-

\begin{tabular}{|ll|}
\hline Table 1. Clinical features & \\
\hline Patients' number & 42 \\
Male/female ratio & $28 / 14$ \\
Average age (range) & $52(26-81)$ \\
Operation type & \\
$\quad$ Total resection & $18(42 \%)$ \\
$\quad$ Subtotal resection & $20(47.6 \%)$ \\
$\quad$ Biopsy & $4(9.5 \%)$ \\
External radiotherapy dose (Gy) & 60 \\
Number of patients receiving chemotherapy & 23 \\
\hline
\end{tabular}

rence or progression. The SRT were applied in single instituation, Ankara Oncology Education and Resourch Hospital between between July 2009 and September 2012. Table 1 shows clinical information of the all patients.Tumors in any location were considered for treatment. The median time from primer radiotherapy to recurrens was 15 months ( $\min =2$, $\max =104)$. The median time from primer radiotherapy to Cyberknife treatment was 19 months (min= $3, \max =106$ ).

Operation methods were total resection in 18 patients, subtotal resection in 20 patients, biopsy only in 4 patients. All patients had received 60 Gy external beam radiotherapy as 2 Gy fractions 5 days per week. Twenty-three patients had also recevied adjuvant chemotherapy. Chemotherapy protocols were temozolomide in 21 patients ( concomitant daily $75 \mathrm{mg} / \mathrm{m}^{2} /$ day with radiotherapy followed by six cycles adjuvan temozolomid $150-200 \mathrm{mg} / \mathrm{m}^{2} /$ day), PVC (Procarbazine, Vinciristine, Carmustine) in 1 patient and CCNU ( Lomustine) in 1 patient. Fourteen of 42 patients were reoperated at the time of recurrence before SRT.

\section{Stereotactic Radiotherapy}

The patients were informed about the potential risks and benefits of robotic fractioned stereotactic radiotherapy (FSRT) and their informed consents were obtained. Computed tomography scans with 1.5 $\mathrm{mm}$ slice intervals and magnetic resonans imaging (MRI) with $3 \mathrm{~mm}$ slice intervals were used for treatment planning. These two images were fused to better visualize tumor and critical structures. The radiation oncologist contoured the tumoral lesions and critical structures including optic nerves, 


\begin{tabular}{|ll|}
\hline \multicolumn{2}{|l|}{ Table 2. Radiosurgical treatment parameters } \\
\hline Target volume (range) & $42 \mathrm{ml}$ (3.60-144 ml) \\
Prescribed dose (range) & $18 \mathrm{~Gy}(12-30 \mathrm{~Gy})$ \\
Prescribed isodose (range & $88 \%(70 \%-93 \%)$ \\
Fraction number (range) & $3(1-5)$ \\
Conformality index (range) & $1.7(1.04-2.4)$ \\
Collimator type & $18(43 \%)$ \\
$\quad$ Fixe & $24(57 \%)$ \\
\multicolumn{1}{|l}{ Iris } & \\
\hline Mean values are showed with ranges in parentheses
\end{tabular}

brain stem, eyes and optic chiasma. Planning tumor volume (PTV) was defined with 1-2 mm margin from gross tumor volume ( GTV). A non-isocentric conformal planning with multipl beams (100-150 beams) and inverse planning methods was used to deliver high doses to target volume while minimizing dose to the critical structures. For treatment the patient was placed in the treatment position with the thermoplastic mask. Bony anatomy of the skull was used as a reference for tracking. X-ray images acquired in real time in treatment position. Digitally reconstructed radiograph (DRR) was used as a reference. Differences of the skull positions between the DRR and the $\mathrm{x}$ - ray images were calculated and corrected. During treatment delivery, $\mathrm{x}$ - ray images were taken every 1-3 beams and the robot adjusted its' position to correct for any residual rotations and translations.

SRT treatment parameters are summarized in Table 2.Treatment was delivered in 1-5 fractions (mean 3). Mean conformality index was 1.7 (1.04-2.4). Iris collimator was used in 24 patients $(57 \%)$. The mean target volume was $42 \mathrm{ml}$ (range, 3.60- 144 $\mathrm{ml}$ ). The mean prescribed dose was $18 \mathrm{~Gy}$ ( range, 12-30 Gy).

\section{Follow-Up}

Clinical and radiological response were evaluated every three months with MRI images.

\section{Statistical Method}

Overall survival were estimated with Kaplan- Meier method. Patient, tumor and treatment related variables were analyzed by univariate analysis.

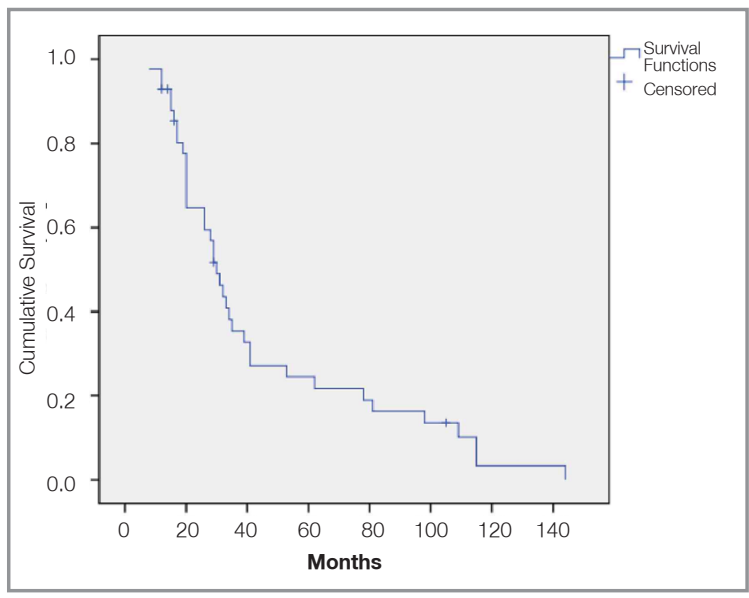

Figure 1. Overall survival of 42 patients

\section{RESULTS}

Median follow-up time from diagnosis was 30 months (range, 8-144 months). Figure 1 shows overall survival of 42 patients. Median follow-up time from stereotactic radiotherapy (SRT) was 10 months (range, 1-38 months).

Median survival from diagnosis were 28 months for glioblastoma multiforme (GBM) patients and 41 months for patients with anaplastic glial tumors $(\mathrm{p}=0.002)$ (Figure 2). Median survival after completion of SRT was 8 months for GBM patients and 11 months for grade 3 patients ( $\mathrm{p}=0.157)$. ( Figure $3)$.

Out of 42 patients, 23 received chemotherapy prior to SRT. The median survival after diagnosis were 28 months and 41 months for patients who received chemotherapy and who didn't receive, respectively $(\mathrm{p}=0.002)$. Median survival after SRT were 9 months and 11 months for patients who received chemotherapy and didn't chemotherapy , respectively $(\mathrm{p}=0.436)$.

The median survival starting from diagnosis were 26 months for patients with gross tumor volume $\leq 10$ $\mathrm{ml}$ and 32 months for patients with tumor volume $>10 \mathrm{ml}(\mathrm{p}=0.265)$. The median survival after completion SRT were 9 months for patients with gross tumor volume $\leq 10 \mathrm{ml}$ and 10 months for patients gross tumor volume $>10 \mathrm{ml}(\mathrm{p}=0.983)$. Although stereotactic radiosurgery is generally preferred for lesions smaller than $10 \mathrm{ml}$ in diameter,in this study most of the these patients $(90.9 \%)$ received FSRT. So we are able to compare results of these two groups ( $\leq 10 \mathrm{ml}$ lesions vs $>10 \mathrm{ml}$ ). 


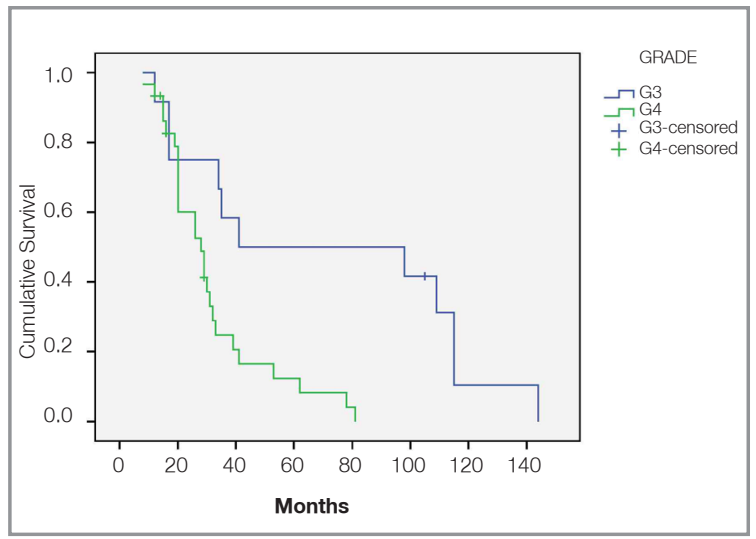

Figure 2. Median survival from diagnosis for patients with grade 3 and grade 4 gliomas

The median survival after initial diagnosis were 30 months for patients reoperated at the time of recurrence and 29 months for patients who were not reoperated $(\mathrm{p}=0.239)$. The median survival after SRT were 10 months for patients reoperated and 9 months for patients who were not reoperated $(\mathrm{p}=$ 0.827).

Complications: Vision impairment secondary to brain necrosis was seen in two patients.Asymptomatic brain necrosis was seen in four patients which was corrected with magnetic resonance spectroscopy.

\section{DISCUSSION}

Stereotactic radiosurgery and radiotherapy methods have been used so far fot the treatment of recurrent GBM and anaplastic glial tumors. ${ }^{13,14,15}$

The Gammaknife (Elekta AB,Stockholm, Sweden) system uses Cobalt 60 radiation source. This system requires invasive immmobilization methods to prevent patient immobilization. Robotically guided stereotactic radiotherapy and radiosurgery system (Cyberknife, Accuray Inc, Sunnyvale, CA,USA) does not require invasive immobilization methods. It uses image guidance system and computer controlled robot to correct patient movement during treatment. So, brain treatment with Cyberknife system is completely noninvasive method of delivering stereotactic radiosurgery and radiotherapy.

In this study, we examined survival outcomes of stereotactic radiotherapy in the recurrent high grade glioma patients treated in our center.

Survival following stereotactic radiosurgery for GBM with Gammaknife has been explored. , $, 6,17-20^{-2}$

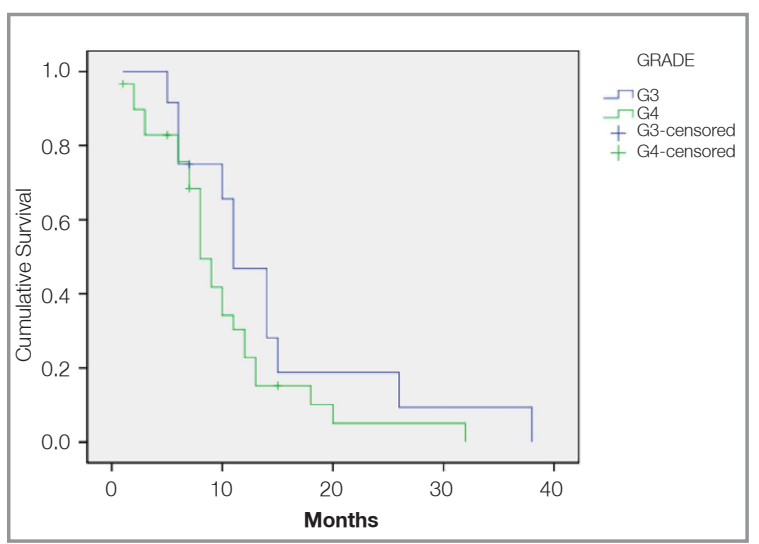

Figure 3. Median survival from SRT for patients with grade 3 and grade 4 gliomas

Pouration N. et al reported retrospectively the treatment results of 48 patients with pathologically proven GBM .Patients treated at the time of progression had significantly longer overall survival than those treated on initial presentation (17.4 vs 15.1 months. $\mathrm{p}=0.003)$. On multivariate analysis, patients with more extensive resections had significantly better survival. $^{5}$

There are limited studies about glial tumor treatment with CyberKnife, stereotactic radiotherapy because of short history of this system. . $8,13,14,15,21,22^{2}$

Alan T. Villavicencio et al. reported survival after stereotactic radiosurgery for newly diagnosed and recurrent glioblastoma multiforme with a multicenter experience. 8 In this study, twenty patients underwent CyberKnife treatment at the time of initial diagnosis, twenty-six patients were treated at the time of tumor recurrence or progression. The median survival from the diagnosis for the patients treated with CyberKnife as an initial clinical therapy was 11.5 months compared to 21 months fort the patients treated at the time of tumor recurrence or progression. This difference was statistically significant $(p=0.0004)$. The median survival from CyberKnife treatment was 9.5 months and 7 months for patients in the newly diagnosed and recurrent GBM groups $(\mathrm{p}=0.79)$. They concluded that there is no appearent survival advantage of using CyberKnife for the initial management of GBM patients, and they suggest that it should be reserved for patients whose tumors recur or progress after conventional therapy. 8

Kong DS et al. reported outcomes of 114 patients with recurrent malign glioma who were treated with stereotactic radiosurgery between 2000-2006. ${ }^{15}$ 
Clinical outcome were analyzed and compared with the historical control group who were treated at the same institution between 1995 and 1999. Compared with historic control group, stereotactic radiosurgery significantly prolonged survival as a salvage treatment in patients with recurrent glioblastomas (23 months vs 2 months, $\mathrm{p}<0.001$ ), but it wasn't found to provide a significant survival benefit in patients with recurrent grade 3 gliomas (37.5 months vs 26 months; $\mathrm{p}=0.789$ ).

The prognosis of patients with GBM generally is poor and median survival time approximately is one year. In our study, the median survival from the diagnosis were 28 months for GBM patients and 41 months for grade 3 astrocytoma patients. Our results are similar with the other reports which are reported survival advantage of stereotactic radiotherapy for recurrent tumors. ${ }^{8,15}$ We saw survival advantage in patients treated with stereotactic radiotherapy at the time of tumor recurrence or progression (28 months). We agree that stereotactic radiotherapy should reserve at the time of tumor recurrence or progression after conventional radiotherapy.

Median survival of grade 3 astrocytoma patients is aproximately three years. In our study, the median survival from diagnosis was 41 months for grade 3 astrocytoma patients and there's a significant survival advantage when compared to GBM patients (41 months versus 28 months, $\mathrm{p}=0.002$ ). On the other hand, the median survival of grade 3 astrocytoma patients after completion of SRT was similar with GBM patients ( 11 months versus 8 months, $\mathrm{p}=$ $0.157)$. It can be related that the mean recurrence time from diagnosis is longer than GBM patients (41 months versus 18 months).

In this study, 14 patients had salvage operation at the time of recurrence prior to SRT. The median survival from SRT is slightly better in these patients, but it wasn't statistically significant (10 months versus 9 months, $\mathrm{p}=0.827$ ).

There are some reports which represent survival advantage of temozolomide treatment especially in the glioblastoma multiforme patients. ${ }^{1,2,3}$ On the contrary, in the current study we found the median survival is statistically better in patients without chemotherapy (41 months versus 28 months, $\mathrm{p}=$ $0.002)$. We assumed that, this could be related with the most of the patients (60\%) who didn't receive chemotherapy had grade 3 astrocytoma.

\section{CONCLUSION}

Reirradiation is one of the treatment option for recurrent glial tumors. Stereotactic radiotherapy can be an effective treatment modality for recurrent high grade glial tumors. Although survival from diagnosis is better in anaplastic tumors, survival from stereotactic radiotherapy are similar in both anaplastic tumors and glioblastom.

\section{REFERENCES}

1. Athanassiou H, Synodinou M, Maragoudakis E, et al. Randomized phase II study of temozolomide and radiotherapy compared with radiotherapy alone in newly diagnosed glioblastoma multiforme. J Clin Oncol 23: 2372-2377, 2005.

2. Stewart LA. Chemotherapy in adult high grade glioma: a systematic review and meta-analysis of individual patient data from 12 randomised trials. Lancet 359: 1011-1018, 2002.

3. Stupp R, Mason VP, van den Bent MJ, et al. Radiotherapy plus concomitant and adjuvan temozolomide for glioblastoma. N Engl J Med 352: 987-996, 2005.

4. Walker MD, Green SB, Byar DP, et al. Randomised comparisons of radiotherapy and nitrosoueras for the treatment malignant glioma after surgery. N Engl J Med 303: 1323-1329, 1980.

5. Pouration N, Crowlwy RW, Sherman JH, et al. Gama Knife radiorurgery after radiation therapy as an adjunctive treatment for glioblastoma. J Neurooncol 94: 409-418, 2009.

6. Biswas T, Okunieff P, Schell MC, et al. Stereotactic radiosurgery for glioblastoma:retrospective analysis. Radiat Oncol 17: 4-11, 2009.

7. Sanghavi S, Skrupsky R, Badie B. Recurrent malign gliomas treated with radiosurgery. J Radiosurg 2: 119-125, 1999.

8. Villavicencio AT, Burneikiene S, Romanelli P, et al. Survival following stereotactic radiosurgery for newly diagnosed and recurrent glioblastoma multiforme. Neurosurg Rev 32: 417424, 2009.

9. Brem H, Piantadosi S, Burger PC, et al. Placebo-controlled trial of safety and efficacy of intraoperative controlled delivery by biodegradable polymers of chemotherapy for recurrent gliomas. The Polymer-brain Tumor Treatment Group. Lancet 345: 1008-1012, 1995.

10. Hess KR, Wong HT, Jaeckle KA, et al. Response and progression in recurrent malign glioma. Neurooncol 1: 282-288, 1999.

11. Nieder C, Grosu AL, Molls M et al. A comparison of treatment results for recurrent malign gliomas. Cancer Treat Rev 26: 397-409, 2002.

12. Niede C, Wiedenmann N, Andratschke, et al. Current status of angiogenesis inhibitors combined with radiotherapy. Cancer Treat Rev 32: 348-364, 2006. 
International Journal of Hematology and Oncology

13. Fokas E, Wacker U, Gross MW, et al. Hypofractionated stereotactic reirradiation of recurrent glioblastomas : a beneficial treatment option after high-dose radiotherapy? Strahlenther Onkol 185: 235-240, 2009.

14. Romanelli P, Conti A, Ponteriero A, et al. Role of stereotactic radiosurgery and fractioned stereotactic radiotherpy for the treatment of recurrent GBM. Neurosurg Focus 27: E8, 2009.

15. Kong DS, Lee JI, Park K, et al. Efficacy of stereotactic radiosurgery as a salvage treatment for recurrent malignant gliomas. Cancer 112: 2046-2051, 2008.

16. Adler JR, Murphy MJ, Chang SD, et al. Image- guided robotic radiosurgery. Neurosugery 44: 1299-1307, 1999.

17. Whang CJ, Kwan Y. Gamma knife radiosurgery for malignant tumors. J Korean Med Sci 10: 379-387, 1995.

18. Nwokedi EC, DiBiase SJ, Jabbour S, et al. Gamma knife stereotactic radiosurgery for patients with glioblastoma multiforme. Neurosurgery 50: 41-47, 2002.

19. Larson DA, Prados M, Lamborn KR, et al. Phase II study of high central dose gamma knife radiosurgery and marimastat in patients with recurrent malign glioma. Int $\mathrm{J}$ Radiat Oncol Biol Phys 54: 1397-1404, 2002.

20. Regine WF, Patchell RA, Strottmann JM, et al. Combined stereotactic split-course fractioned gamma knife radiosurgery and convencionel radiation therapy for unfavorable gliomas: $\mathrm{A}$ phase I study. J Neurosurg 93: 37-41, 2000.

21. Yoshikawa K, Saito K, Kajiwara K, et al. CyberKnife stereotactic radiotherapy for patients with malignant glioma. Minim Invasive Neurosurg 49: 110-115, 2006.

22. Lipani JD, Jackson PS, Soltys SG, et al. Survival following CyberKnife radiosurgery and hypofractionated radiotherapy for newly diagnosed glioblastoma multiforme. Technol Cancer Res Treat 7: 249-55, 2008.

\section{Correspondence}

Dr. Gülhan Güler AVCI

Süvari mahallesi

1765. sok. No: $6 \mathrm{C} / 11$

Etimesgut

ANKARA / TURKEY

Tel: (+90.312) 3360909

Fax: +90.312) 3369681

e-mail: drgulhanguler@hotmail.com 